\title{
Composição química e resistência mecânica da base de braquetes "Straight-Wire"
}

\author{
Luciana de Paula GONTIJO*, Enio Tonani MAZZIEIRO**, Janes LANDRE JÚNIOR***
}

\begin{abstract}
Resumo
Esse trabalho objetivou comparar as durezas superficiais e as características metalográficas das bases de braquetes "straight-wire" de quatro marcas comerciais: Morelli, Abzil Lancer, Unitek e A-Company. As durezas superficiais foram avaliadas por meio de um teste de dureza realizado com o auxílio de um microdurômetro. Os resultados indicaram diferenças entre as marcas comerciais testadas onde os braquetes da A-Company apresentaram os valores mais altos de dureza (314 HV), seguidos da Unitek (325 HV), Abzil (230 HV) e Morelli (192 HV). As características metalográficas das bases de braquetes foram avaliadas por meio de um espectrômetro, onde observou-se a presença de elementos de liga como o cromo, o níquel, o silício, o cobre, o alumínio, o enxofre e o nióbio. A quantidade de cada elemento de liga variou entre as marcas, provavelmente devido ao processo de fabricação industrial, mas sem interferir na qualidade final da liga.
\end{abstract}

Palavras-chave: Braquetes. Base de braquete. Dureza Vickers. Metalografia.

\section{INTRODUÇÃO}

A evolução dos acessórios ortodônticos é marcada por uma busca incessante de se posicionar os dentes em todos os três planos do espaço. $\mathrm{O}$ aparelho mais difundido atualmente utiliza braquetes do tipo "edgewise" modificados, onde foram incorporadas em suas estruturas as dobras de $1^{\mathrm{a}}, 2^{\mathrm{a}}$ e $3^{\mathrm{a}}$ ordem, com a finalidade de se atingir o controle tridimensional do movimento dentário utilizando-se arcos retos. Esse sistema recebeu a denominação de "straight-wire".

De acordo com Andrews ${ }^{1,2,3}$ a orientação dos dentes em boa oclusão e a morfologia dentária mostram-se suficientemente similares, de paciente para paciente, o que permite o uso generalizado de braquetes pré-torqueados, pré-angulados e com desvios compensatórios das espessuras dos dentes em conjunto com arcos retos, alcançando automaticamente uma boa oclusão. Contudo, para que isso ocorra, torna-se necessário que os braquetes possuam uma estabilidade estrutural, isto é, que não se deformem durante o tratamento.

Os materiais utilizados na confecção dos aparelhos devem ser manufaturados, de tal forma que as dimensões internas do encaixe do "slot" sejam precisas, pelo menos em um milésimo de polegada. Além disso, devem ser resistentes às deformações decorrentes das forças da mastigação a que estão submetidos ${ }^{11}$.

O metal mais utilizado na confecção de braquetes é o aço inoxidável austenítico (AISI aço inoxidável tipo 316L), o qual possui $18 \%$ de cromo,

* Aluna do curso de Mestrado em Ortodontia do COP-PUCMinas.

** Doutor em Ortodontia. Coordenador do Mestrado em Ortodontia do COP-PUCMinas. Orientador do trabalho.

*** Doutor em Engenharia Mecânica. Professor do Departamento de Engenharia da PUCMinas. Co-Orientador do trabalho. 
8\% de níquel, 2 a 3\% de molibdênio e baixo conteúdo de carbono ${ }^{10}$. As propriedades mecânicas deste tipo de aço, como boa resistência mecânica e tenacidade, boas características de fabricação, resistência moderada ao calor, e ótima resistência à corrosão atmosférica e química, o tornam bastante atrativo ${ }^{9}$.

Alguns elementos de liga podem ser incorporados ao aço, alterando as suas propriedades. A introdução do níquel melhora consideravelmente a resistência à corrosão e a resistência à oxidação a altas temperaturas e, além disso, forma uma camada de óxido que protege o aço espontaneamente. $\mathrm{O}$ cromo atua como anti-oxidante. $\mathrm{O}$ molibidênio fornece maior resistência à corrosão em soluções clorídricas, e o cobre ajuda o molibidênio no aumento da resistência à corrosão, aumentando-a apreciavelmente, porém com decréscimo da ductabilidade $^{8}$.

O silício age como o molibidênio e é usado para aumentar a resistência mecânica e a resistência à oxidação. Geralmente, o silício é mantido em pequenas quantidades apenas para "acalmar" os aços. O alumínio é utilizado para desoxidar e refinar o grão, diminuindo o seu tamanho. O nióbio é usado para serviços em altas temperaturas, pois pequenos teores de nióbio elevam o limite de escoamento do aço e, em menor proporção, o limite de resistência à tração ${ }^{8}$.

Observando-se os catálogos dos fabricantes de braquetes nota-se que as diversas marcas comerciais de acessórios ortodônticos utilizam o aço inoxidável para a produção industrial. Contudo, nenhuma informação a respeito de suas ligas é fornecida, a não ser quando se trata do nível de níquel incorporado. Especial atenção é dada a esse elemento devido à sua conhecida capacidade alérgica tecidual ${ }^{4,5}$. Contudo a adição de outros elementos de liga podem influenciar a resistência mecânica arquitetural dos braquetes, influenciando sua resistência à deformação.

$\mathrm{Na}$ engenharia, o controle e o ensaio de produtos siderúrgicos são realizados quando se torna necessário ter uma idéia aproximada da natureza e fabricação de certos materiais metálicos ${ }^{9}$.

Os ensaios mecânicos determinam valores numéricos que caracterizam, de certa maneira, as propriedades mecânicas do material. Estas determinações são feitas com auxílio de máquinas apropriadas que, ao mesmo tempo que aplicam o esforço, acusam a sua intensidade. $\mathrm{O}$ ensaio pode ser feito sobre peças inteiras ou sobre pedaços de forma conveniente (corpos de prova) extraídos das peças. Neste caso, os resultados obtidos representam as propriedades mecânicas do material de que a peça é feita e não propriamente as da peça em si, como um todo .

O ensaio de dureza é largamente utilizado na especificação e comparação de materiais. Intrinsecamente traduz uma característica referente à superfície do metal, entretanto, para materiais homogêneos, é tomado como uma propriedade global e representativa do material. Dentre os vários métodos utilizados para se avaliar a dureza, o Método Vickers, é muito indicado quando se deseja a determinação da dureza de constituintes individuais de uma certa estrutura, ou ainda de materiais frágeis e peças de pequenas dimensões ou espessura ${ }^{12}$.

O termo dureza assume diversos significados devido à existência de uma grande divergência de opiniões entre os estudiosos das mais diversas áreas, portanto, não é possível encontrar um conceito único para esta característica. Ainda assim, o ensaio é utilizado para que se possam efetuar comparações entre os mais distintos materiais. Em geral, para os metais, a dureza implica em uma resistência à deformação plástica ${ }^{6}$.

Enquanto os ensaios siderúrgicos visam testar as características estruturais dos materiais metálicos, a análise química dosa os elementos que intervêm na composição do material. Para os aços comuns determinam-se as percentagens de carbono, silício, manganês, fósforo, enxofre. Nos produtos comuns existem ainda outros elementos como o oxigênio, o nitrogênio, o hidrogênio, que também 
influenciam nas propriedades do metal, mas como ocorrem, geralmente, em baixa percentagem e são de dosagem mais trabalhosa, sua determinação deixa habitualmente de ser feita ${ }^{9}$.

$\mathrm{Na}$ espectrografia, com o auxílio de um espectrômetro, pode-se fazer análises mais rápidas e simultâneas de numerosos elementos, detectando qualquer metal estranho que entre na composição do material examinado, mesmo que seu teor seja relativamente pequeno.

Esse trabalho intencionou verificar as características estruturais e a composição química do aço utilizado na fabricação de braquetes metálicos comumente encontrados no mercado, determinando-se, respectivamente, a resistência à deformação quando submetidos ao teste de dureza Vickers e a porcentagem dos principais elementos de liga na espectografia.

\section{MATERIAIS E MÉTODOS Amostra}

Para a realização deste trabalho, utilizou-se braquetes das marcas comerciais "Morelli" (modelo: 10.10.901-CRTZ-01 - lote20000809, prescrição Roth-.022" x.030"), "Abzil Lancer" (modelo: Kirium Line .022", prescrição Roth), "Unitek" (modelo: Gemini mesh .022" prescrição Roth ref: 119-701) e "A-Company" (modelo: True StraightWire, tamanho médio, prescrição Roth), obtidos através dos seus representantes comerciais.

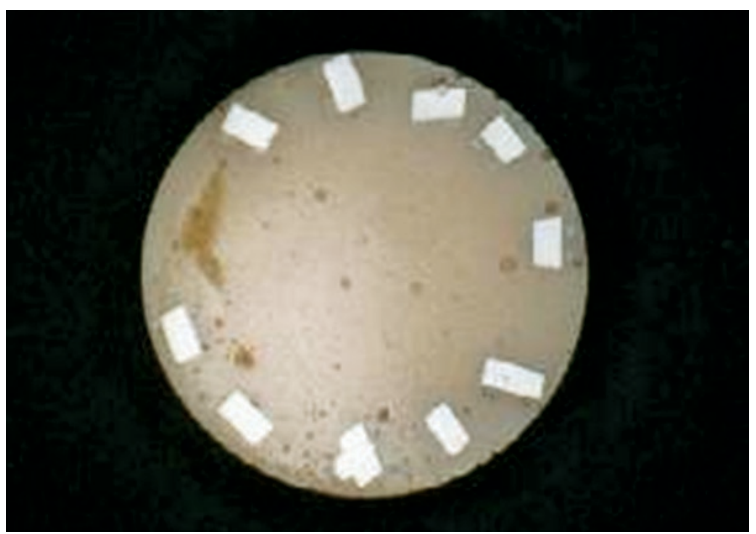

FIGURA 1 - Amostras embutidas em moldes acrílicos e preparadas para o teste de Dureza Vickers, segundo metodologia descrita por COLPAERT ${ }^{9}$.

\section{Métodos de análises}

Teste de Dureza Vickers

Para o teste de dureza Vickers, as amostras dos quatro fabricantes foram imersas em moldes empregando-se resina acrílica (co-polímero de acrílico auto polimerizante) e catalisador líquido, segundo método descrito por Colpaert ${ }^{9}$, em 1974. Os braquetes foram posicionados com a superfície da base voltada para a área de teste (Fig. 1).

Após as amostras terem sido embutidas em resina acrílica procedeu-se a seqüência de lixamento, segundo metodologia de Colpaert ${ }^{9}$, com lixas de granulações 120, 220, 320, 400, 500, 600, preparando as superfícies testes.

Com o intuito de se evitar grandes variações nos valores obtidos nos testes de dureza, seja pela recuperação elástica, seja pela obtenção de impressões muito pequenas que poderiam induzir a erros significativos de leitura, realizou-se uma avaliação piloto da carga ideal para execução dos ensaios. Nesse estudo piloto, escolheu-se aleatoriamente a marca "Morelli", e foram testados 3 braquetes desta mesma marca; as cargas empregadas foram de 0,5, 1, 2, 3, 4 e $5 \mathrm{Kgf}$. O aparelho utilizado foi o microdurômetro Brivisor KL 2 da Georg Reicherter (Fig. 2).

Os resultados do teste piloto demonstraram que com a aplicação de uma carga de $5 \mathrm{Kgf}$, os valores de dureza obtidos para os três braquetes apresentaram uma menor dispersão (Tab. 1, Gráf. 1). Esse valor foi tomado com referência para os demais testes.

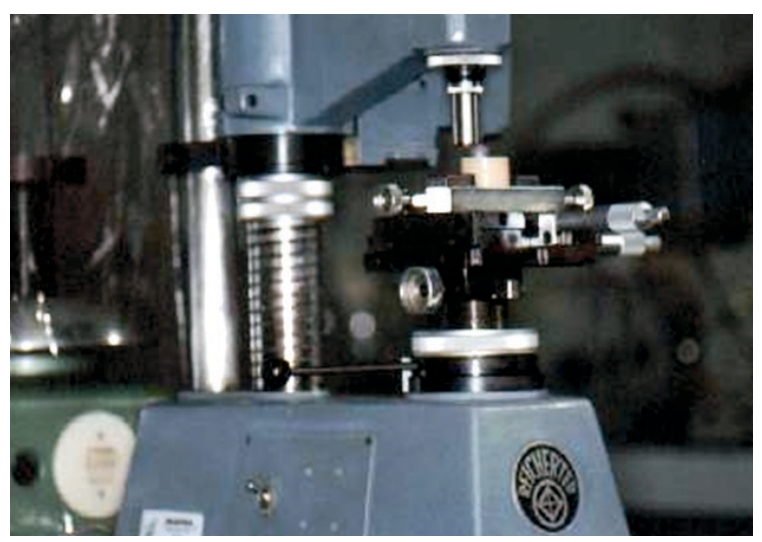

FIGURA 2 - Microdurômetro Brivisor KL 2. 
A dureza foi avaliada em três pontos diferentes de cada corpo de prova de cada marca comercial, sendo o resultado expresso na sua média aritmética.

\section{Perfil de dureza}

Os braquetes da marca "Morelli" aprepresentam soldas em suas estruturas. Dessa forma, a influência da soldagem na dureza do material também foi testada. Para isso, os braquetes da marca

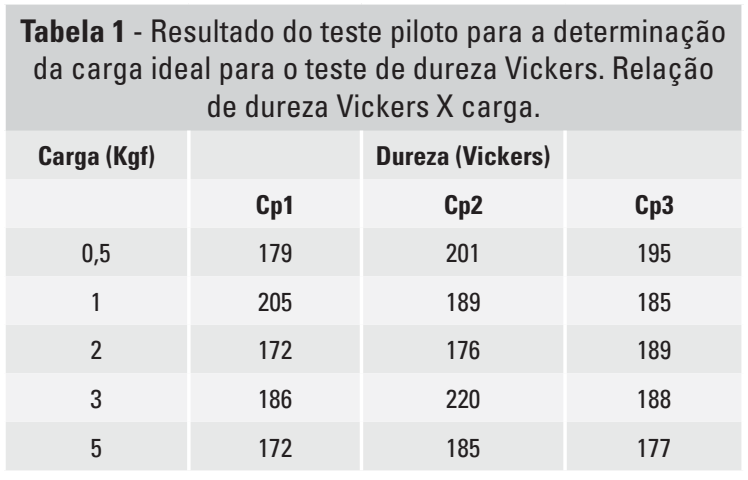

Cp - Corpo de prova

\begin{tabular}{|c|c|c|c|c|}
\hline \multicolumn{3}{|c|}{ Tabela 2 - Resultados do teste de dureza Vickers para os } \\
diferentes fabricantes. \\
\hline Identificação & \multicolumn{3}{|c|}{ Dureza HV5 } \\
& Amostra 1 & Amostra 2 & Amostra 3 & $\begin{array}{c}\text { HVÉDIA } \\
\text { MÉn }\end{array}$ \\
\hline MORELLI & 195 & 190 & 192 & 192 \\
\hline ABZIL & 227 & 230 & 232 & 230 \\
\hline A-COMPANY & 330 & 340 & 352 & 341 \\
\hline UNITEK & 321 & 325 & 330 & 325 \\
\hline
\end{tabular}

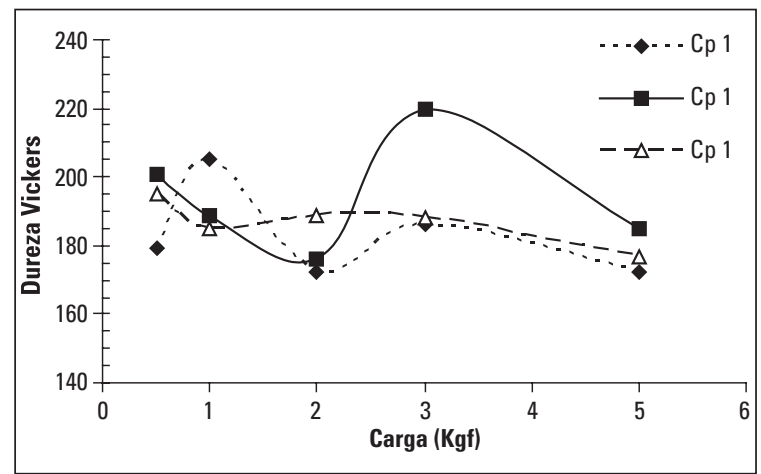

GRÁFICO 1 - Gráfico de dispersão das cargas testes aplicadas. Com a carga de $5 \mathrm{Kgf}$ obteve-se resultados com menor dispersão.
"Morelli", foram submetidos a um teste para a avaliação do perfil de dureza da sua base. Para tanto, dois braquetes (corpos de prova 1 e 2) foram embutidos em moldes, segundo metodologia descrita anteriormente ${ }^{9}$ expondo e preparando sua base. Empregou-se, nesta operação, uma carga mais baixa (2 Kgf). O teste foi feito no sentido mésiodistal da base do braquete, nas distâncias de $0.2,0.4,0.6,0.8,1,1.2$ e $1.4 \mathrm{~mm}$.

\section{Análise química}

Para a realização da análise química dos braquetes, utilizou-se o espectrômetro da marca Noran, que é capaz de fazer a análise quantitativa dos elementos de liga (Fig. 3). Este aparelho emite radiações, em freqüências específicas, predeterminadas, para cada elemento; então durante a análise do material, realiza-se uma varredura dessas freqüências e quando encontrada, avalia-se a sua amplitude.

\section{RESULTADOS}

Os resultados dos testes serão apresentados a seguir, de forma descritiva, em valores absolutos e representam as características individuais de cada aço utilizado na fabricação dos acessórios.

\section{Teste de dureza Vickers}

Através do teste de dureza Vickers, com a carga selecionada no estudo piloto de $5 \mathrm{Kgf}$, realizado em três locais diferentes do mesmo braquete, obteve-se a dureza média final de cada

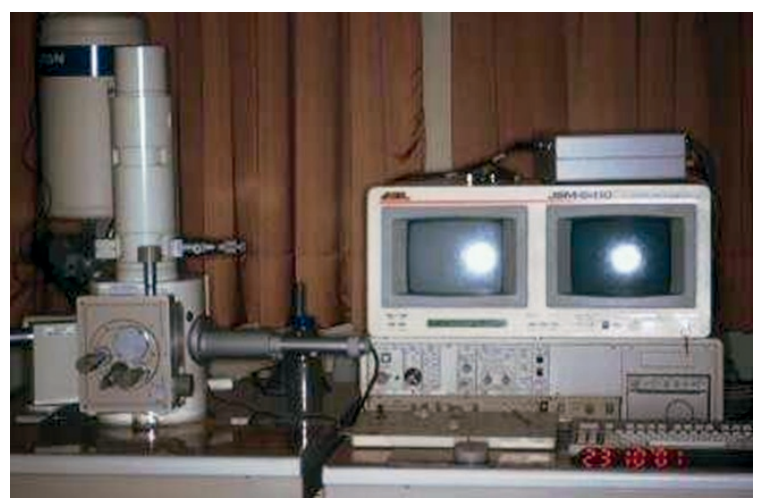

FIGURA 3 - Espectrômetro da marca Noran. 
Tabela 3 - Perfil de dureza dos braquetes da marca Morelli, avaliados com uma carga de $2 \mathrm{Kgf}$.

Distância- mm

\begin{tabular}{|c|c|c|}
\hline & Cp 1 & Cp 2 \\
\hline 0,2 & 154 & 143 \\
\hline 0,4 & 165 & 149 \\
\hline 0,6 & 169 & 151 \\
\hline 0,8 & 163 & 161 \\
\hline 1 & 167 & 131 \\
\hline 1,2 & 163 & 167 \\
\hline 1,4 & 169 & 152 \\
\hline
\end{tabular}

Cp - Corpo de prova

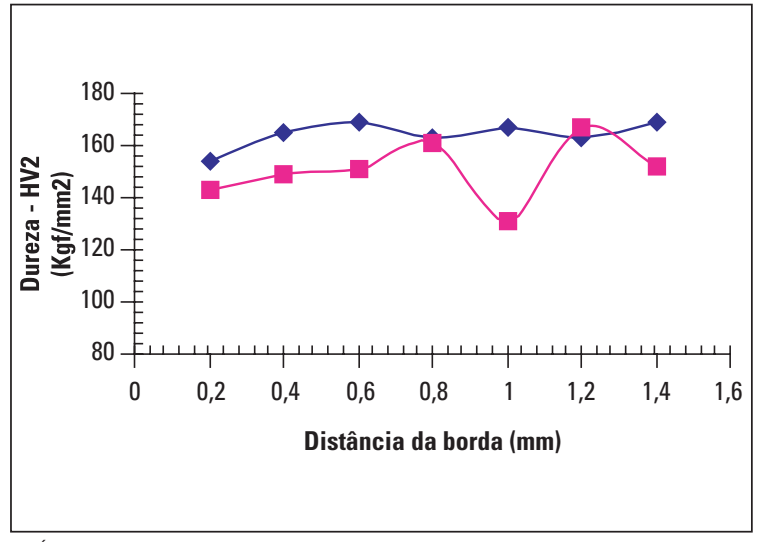

GRÁFICO 2 - Perfil de dureza dos braquetes da marca Morelli.

\begin{tabular}{|c|c|c|c|c|c|c|c|c|}
\hline Marca & $\mathrm{Fe}$ & $\mathrm{Si}$ & $\mathrm{Cr}$ & $\mathrm{Ni}$ & Cu & Al & $S$ & $\mathbf{N b}$ \\
\hline Morelli & 69.51 & 1.64 & 19.20 & 8.19 & - & 0.86 & 0.60 & - \\
\hline A-Company & 73.14 & 1.30 & 21.25 & 3.25 & - & - & - & 1.06 \\
\hline Unitek & 74.12 & 1.13 & 17.57 & 4.49 & 2.68 & - & - & - \\
\hline Abzil & 71.27 & 1.01 & 19.40 & 8.32 & - & $\ldots$ & - & - \\
\hline
\end{tabular}

marca comercial. Os resultados para cada marca avaliada podem ser observados na tabela 2 .

\section{Perfil de dureza}

A tabela 3 mostra as durezas obtidas em cada uma das distâncias $(0,2 ; 0,4 ; 0,6 ; 0,8 ; 1 ; 1,2$ e 1,4 $\mathrm{mm}$ ), para os braquetes (corpos de prova 1 e 2 ) da marca "Morelli". Esses resultados podem ser melhor visualizados no gráfico 2.

\section{Análise química}

A tabela 4 apresenta o resultado, em porcentagem, dos elementos químicos de cada amostra analisada. É importante salientar que em alguns casos, não há presença de determinado elemento de liga, ou a sua porcentagem mostrou-se tão baixa que o espectrômetro não foi capaz de identificar.

\section{DISCUSSÃO}

\section{Teste de dureza Vickers}

A dureza Vickers foi selecionada para testar a resistência superficial dos braquetes. A carga de $5 \mathrm{Kgf}$ selecionada para o teste de dureza dos braquetes analisados baseou-se em um estudo piloto onde determinou-se o valor de carga com uma menor dispersão, o que implica, talvez, em uma menor influência da recuperação elástica ou mesmo em um menor erro de leitura. $\mathrm{O}$ teste de dureza mostrou que as marcas analisadas apresentaram durezas diferentes (Tab. 1). Verificou-se que valores mais altos de dureza foram obtidos para os da marca "ACompany" (341 HV), seguidos pela marca "Unitek" (325), "Abzil" (230) e "Morelli" (192).

Segundo Souza ${ }^{12}$, para um metal, a dureza está diretamente ligada à sua resistência à deformação 
plástica. A resistência à deformação plástica é uma boa característica, pois permite a aplicação de forças nos braquetes, seja através da colocação de fios espessos, da retração ou do uso de acessórios auxiliares acoplados aos mesmos, sem que alterem suas características incorporadas, dobras de $1^{\text {a }}, 2^{\text {a }} \mathrm{e}$ $3^{\mathrm{a}}$ ordens, permitindo o correto controle tridimensional do dente durante o movimento ortodôntico ou a resistência à deformação das aletas e canaletas dos braquetes.

Contudo, nenhum estudo quantificou quais os valores mínimos necessários que os braquetes devem possuir nos testes de dureza para suportarem as forças das mecânicas ortodônticas ou mesmo da mastigação. Dessa forma, não podemos determinar uma superioridade de uma marca comercial. Porém, pode-se observar que a "Morelli" apresentou resultado bastante inferior às demais marcas, sugerindo maior tendência à alteração arquitetural de sua base.

No aspecto clínico, atualmente, muitos ortodontistas têm reciclado os seus braquetes. Nesse caso, a dureza superficial do material torna-se fundamental. A remoção dos braquetes, realizada por meio de alicate, incorpora uma pressão sobre o acessório descolando-o do dente. Aquele que apresentar o aço mais resistente sofrerá menor distorção durante sua remoção, estando mais apto para a reciclagem.

Por apresentar o pior resultado no teste de dureza Vickers e considerando que a "Morelli" é um dos fabricantes analizados nesse trabalho que utiliza o processo de soldagem dos braquetes, procurou-se avaliar a influência da solda na dureza do material, através do levantamento do perfil de dureza no sentido mésiodistal da base do acessório. A análise da tabela 1 e do gráfico 1, sugere que a carga utilizada no teste ( $2 \mathrm{Kgf}$ ) mostrou-se elevada e, em algumas situações a amostra ensaiada foi totalmente perfurada, o que levou à obtenção de valores muito baixos. Não foram realizados testes com aplicações de valores mais baixos de cargas, devido à di- ficuldade na leitura das impressões, pois estas se tornaram cada vez menores com a redução da carga. Portanto, esses resultados apresentam uma baixa confiabilidade para este caso em específico. Apesar disso, decidimos manter a sua apresentação, alertando para a possibilidade da influência dos procedimentos de soldagem na fabricação dos braquetes.

De acordo com a fabricação do braquete, se injetado ou soldado, os resultados devem ser diferenciados, pois as estruturas soldadas tendem a se deformar mais facilmente. Em um processo mecânico onde existe uma solda, nota-se uma maior possibilidade de ocorrer deformações se comparado a um processo de conformação.

\section{Análise química}

$\mathrm{Na}$ análise química do aço utilizado para a fabricação dos braquetes buscou-se avaliar a qualidade e o tipo de metal usado. Para a sua realização utilizou-se um espectrômetro da marca Noran, que é capaz de fazer a análise quantitativa dos elementos de liga.

Segundo Chiaverini ${ }^{8}$, os aços inoxidáveis austeníticos possuem o teor médio de cromo de 18\% e de níquel de $8 \% \mathrm{O}$ cromo atua como anti-oxidante. A introdução do níquel melhora consideravelmente a resistência à corrosão e a resistência à oxidação.

Em um dos raros trabalhos na literatura, Platt $^{10}$ verificou a presença de oxidação nos acessórios ortodônticos e afirmou que o metal utilizado na fabricação dos braquetes ortodônticos era aço inoxidável do tipo austenítico, o que foi confirmado por meio dos resultados da análise química feita nas amostras. Na tabela 4 podemos verificar que os valores médios de cromo e níquel encontrados, respectivamente foram: $19.20 \%$ e $8,19 \%$ nos braquetes da "Morelli", $21.5 \%$ e 3,25\% nos da "A-Company", $17.57 \%$ e 4,49\% nos da "Unitek" e 19,40 \% e 8,32\% na "Abzil".

Além destes componentes, cromo e níquel, 
observa-se a presença de outros elementos na composição química dos braquetes analisados. De acordo com Chiaverini ${ }^{8}$, esses elementos podem alterar as propriedades do metal. Entre eles estão o silício, o cobre, o alumínio, o enxofre e o nióbio, sendo que cada um destes elementos confere ao aço uma característica peculiar.

Os elementos de liga responsáveis pela melhora da resistência à corrosão são o cobre, o níquel, o cromo e o silício. O aço utilizado para a fabricação dos braquetes "Morelli" foi o que apresentou um percentual, no total, maior destes componentes, $19.20 \%$ de cromo, $8.19 \%$ de níquel e 1,64 \% de silício (aumenta a resistência mecânica e a resistência à oxidação). Porém, deve-se salientar que todas as marcas apresentaram cromo e silício, indicando que todas possuem resistência à corrosão.

A marca "Morelli" apresentou as maiores quantidades de enxofre, que eleva o limite de escoamento e a usinabilidade do aço, além de apresentar, também, percentual maior de alumínio (desoxida e refina o grão). A presença desses elementos pode estar associada ao tipo de fabricação dos braquetes dessa marca que apresentam soldas. Contudo não podemos afirmar categoricamente sobre essa especulação, pois a totalidade do processo industrial e o tipo de solda utilizado não são do nosso conhecimento.

O nióbio foi encontrado em quantidades maiores na marca "A-Company". Esse elemento permite que o aço seja trabalhado em altas temperaturas, aumenta o limite de escoamento do aço e o limite de resistência à tração ${ }^{8}$. Possivelmente esteja presente para otimizar o processo de fabricação por injeção do metal.

A análise metalográfica demonstrou que todas as marcas comerciais utilizam o aço inoxidável do tipo austenítico. Pequenas variações nos percentuais dos elementos químicos principais desse tipo de aço não comprometem nenhuma das marcas, nem determina uma superioridade entre elas. A incorporação de outros elementos, como o alu- mínio e enxofre na marca "Morelli", o nióbio na "A-Company" e o cobre na "Unitek" podem estar relacionados com os diferentes processos de fabricação desses acessórios ortodônticos.

Correlacionando os resultados metalográficos aos de resistência à deformação, podemos pressupor que o tipo de solda e a técnica de soldagem durante a fabricação dos acessórios da marca "Morelli" possam explicar o baixo resultado encontrado no teste de dureza, uma vez que a qualidade do aço utilizado por esse fabricante não difere das demais marcas comerciais, mas apresenta um resultado extremamente inferior no que se refere à deformação plástica.

\section{CONCLUSÕES}

Diante da metodologia empregada concluiu-se que:

1) Em relação às características estruturais, as marcas comerciais testadas apresentaram diferentes valores ao teste de dureza Vickers, sendo que os valores mais altos foram obtidos pela marca "A-Company" (34l HV), seguidos pela marca "Unitek" (325 HV), "Abzil" (230 HV) e "Morelli" (192 HV). O baixo resultado do teste de perfil de dureza, realizado exclusivamente com a marca Morelli, sugeriu a possibilidade da influência da soldagem durante o processo industrial dos seus acessórios.

2) Em relação à composição química do aço, a espectrografia indicou que todas as marcas pesquisadas utilizam o aço inoxidável do tipo austenítico na fabricação de seus acessórios. As variações nas porcentagens do cromo e do níquel e a presença de alguns outros elementos de liga em cada marca analisada relacionam-se, provavelmente, ao processo de fabricação industrial, porém, sem interferir na qualidade metalúrgica final do aço.

Enviado em: Outubro de 2002 Revisado e aceito: Abril de 2003 


\title{
Superficial hardness and the metallographic characteristics of straight-wire base brackets
}

\begin{abstract}
The objective of this study was to compare the superficial hardness and the metallographic characteristics of the bases of straight-wire brackets. Brackets from four different manufactures were utilized: Morelli, Abzil Lancer, Unitek and A-Company. The superficial hardness test revealed that the A-Company bracket base had the highest value (314 HV) followed by Unitek (325 HV), Abzil (230 HV) and Morelli (192 HV). The presence of variable amounts of chrome, nickel, silicon, copper, aluminum, sulfur and niobium was detected by the spectrometer. The quantity of each element varied according to the brand tested and did not interfere with the quality of the alloy. This variance was most likely due to differences in the process of the fabrication of each manufactures.
\end{abstract}

Key words: Brackets. Base brackets. Hard Vickers. Metalography.

\section{REFERÊNCIAS}

1. ANDREWS, L. F. The straight- wire appliance: arch form, wire bending \& an experiment. J Clin Orthod, Boulder, v. 10, no. 8, p. 581-588, Aug. 1976.

2. ANDREWS, L. F. The straight- wire appliance: explained and compared. J Clin Orthod, Boulder, v.10, no. 3, p.174-195, mar. 1976.

3. ANDREWS, L. F. The straight- wire appliance: origin, controversy, commentary. J Clin Orthod, Boulder, v. 10, no. 2, p. 99-114, Feb. 1976.

4. BASS, J. K.; FINE, H.; CISNEIROS, G. J. Nickel hypersensibility the orthodontic pacient. Am J Orthod Dentofacial Orthop, St. Louis, v. 103, no. 3, p. 280-285, Mar. 1993

5. BLANCO-DALMAU, L.; CARRASQUILLO-ALBERTI, H.; SILVAPARRA, J. A study of nickel allergy. J Prosthet Dent, St. Louis, v. 52, no.1, p.116-119, July 1984

6. BORESI, A. P.; SCHMIDT, R.; SIDEBOTTOM, O. M. Advanced mechanics of materials. 5th ed. New York: J. Wiley, 1993.
7. CASTRO, U. D. Metalografia e ensaios mecânicos: práticas de laboratório.1. ed. Belo Horizonte, 2000.

8. CHIAVERINI, V. Aços e ferros fundidos. 6. ed. São Paulo: ABM, 1990.

9. COLPAERT. H. Metalografia dos produtos siderúrgicos comuns. 3. ed. São Paulo: E. Blucher, 1974.

10. PLATT, J. A.; GUZMAN, A.; ZUCCARI, A.; THORNBURG, D. W.; RHODES, B. F.; OSHIDA, Y.; MOORE, B. K. Corrosion behavior of the 2205 duplex stainless steel. Am J Orthod Dentofacial Orthop, St. Louis, v. 112, no.1, p. 69-79, July 1997.

11. PROFFIT, W. R. Ortodontia contemporânea. 2. ed. Rio de Janeiro: Guanabara Koogan, 1995.

12. SOUZA, S. A. Ensaios mecânicos de materiais metálicos fundamentos teóricos e práticos. São Paulo: E. Blucher, 1982.

Endereço para correspondência
Enio Tonani Mazzieiro
COP-PUCMinas
Av. Dom José Gaspar 500, Coração Eucarístico, prédio 46
CEP: $30535-610$
Belo Horizonte - MG
E-mail: mazzieiro@pucminas.br

Endereço para correspondência

Av. Dom José G

Belo Horizonte - MG

E-mail: mazzieiro@pucminas.br 